\title{
Biopsy Type Disparities in Patients With Melanoma: Who Receives the Standard of Care?
}

\author{
DAVID J. RESTREPO ${ }^{1}$, MARIA T. HUAYLLANI ${ }^{1}$, DANIEL BOCZAR ${ }^{1}$, ANDREA SISTI ${ }^{1}$, \\ EMMANUEL GABRIEL ${ }^{2}$, RICCARDO LEMINI ${ }^{2}$, AARON C. SPAULDING ${ }^{3}$, \\ SANJAY BAGARIA ${ }^{2}$, OSCAR J. MANRIQUE ${ }^{4}$ and ANTONIO J. FORTE ${ }^{1}$ \\ ${ }^{1}$ Division of Plastic Surgery, Mayo Clinic, Jacksonville, FL, U.S.A.; \\ ${ }^{2}$ Department of Surgery, Mayo Clinic, Jacksonville, FL, U.S.A.; \\ ${ }^{3}$ Department of Health Science Research, Mayo Clinic, Jacksonville, FL, U.S.A.; \\ ${ }^{4}$ Division of Plastic Surgery, Mayo Clinic, Rochester, MN, U.S.A.
}

\begin{abstract}
Background/Aim: To analyze whether demographic and facility type characteristics cause inequality in the type of biopsy performed in patients with cutaneous melanoma. Patients and Methods: The skin cancer National Cancer Database was assessed. Men and women of all ages with cutaneous melanoma in situ and malignant melanoma at any stage of the disease were included. Patients were selected who underwent one of the following biopsy types: excisional, punch, shave, or incisional. Bivariate and multivariate analyses were performed. Results: We found that the likelihood of undergoing an excisional biopsy decreased in patients who were: Hispanic [odds ratio $(O R)=0.63$, confidence interval $(C I)=0.55-0.71]$, non-White $(O R=0.66, C I=0.58-0.76)$, older than 80 years (OR=0.77, CI=0.72-0.87), or in Comprehensive Community Cancer Programs (OR=0.33, CI=0.31-0.36), Community Cancer Programs (OR=0.52, CI=0.50-0.54) and Integrated Network Cancer Programs $(O R=0.58, C I=0.55-0.61)$. Conclusion: Our study results demonstrate disparities in biopsy type in the treatment of melanoma.
\end{abstract}

Melanoma is the fifth most common malignancy in the United States (1). Recently published studies have shown that disparities exist in melanoma treatment and outcomes (2-4). However, equality in healthcare delivery to every patient in the US is desired. According to the American Academy of Dermatology guidelines, available in $2001(5,6)$ and to the National Cancer Comprehensive Network Guidelines, available in 1998 (7), excisional biopsy is the standard of treatment and diagnosis for patients that have lesions that raise

Correspondence to: Antonio Jorge Forte, MD, Ph.D, Mayo Clinic Florida, 4500 San Pablo Road, Jacksonville, FL 32224, USA. Tel: +1 9049532073, e-mail: ajvforte@yahoo.com.br

Key Words: Melanoma, biopsy, socioeconomic factors, disparities. suspicion for melanoma. We aimed to analyze the effect that gender, age, race, ethnicity, income, education, insurance, population density, distance from treating facility, facility type, and location have on the type of biopsy used to diagnose patients with cutaneous melanoma.

\section{Patients and Methods}

The National Cancer Data Base (NCDB) is a program of the Commission on Cancer of the American College of Surgeons and the American Cancer Society. It is a nationwide database that collects information of approximately $70 \%$ of all new cases of cancer and $48.4 \%$ of melanoma cases in the United States (7). Integrity checks are run on the submitted data making sure that they are complete and accurate. Otherwise, the cases are returned to the submitting hospital (7). The characteristics and information included in this database allowed us to perform a retrospective cohort study in which we queried the NCDB for patients with melanoma diagnosed between January 1st, 2004 and December 31st, 2015. Men and women, of all ages, with cutaneous melanoma in situ and malignant melanoma at any stage of the disease were included. Our inclusion criteria included patients who had one of the following biopsy types reported: excisional, punch, shave, or incisional. It is important to note that excisional biopsy is different from wide local excision on the NCDB. Patients who did not have type of biopsy data were excluded. Biopsies other than excisional were merged into 'other' biopsies to facilitate statistical analysis. The variables of interest to our study included patient demographic characteristics: Hispanic origin, race, gender, age, insurance status, income (zip code's population average), education (percentage of people without high school diploma within the zip code of residence), population density of the patient's site of residence, and distance from the zip code of residence to the treating institution. Facility characteristics included facility location and facility type.

We examined the association between biopsy type and demographic and facility type characteristics. The patient characteristics associated with excisional versus other types of biopsy were examined using the chi-squared test. Multivariate binary logistic regression was performed to examine how demographic and facility type characteristics influenced the receipt of excisional versus other types of biopsy. The 
model used the following covariates: Hispanic origin, race, gender, age, insurance status, income, education population density of the patient's site of residence, distance from the zip code of residence to the treating institution, facility location, and facility type. Patients with missing data were excluded from multivariate regression. Significance levels were set at a $p$-value of less than 0.05 . Statistical analysis was performed using SPSS 25.0 statistical software (IBM, Armonk, NY, USA).

\section{Results}

Our cohort included 126,488 patients. Of the 126,488 patients included, $72,053(57.0 \%)$ were men, and the mean age was $61.5 \pm 16.13(\mathrm{SD})$ years. In terms of race 123,077 $(97.3 \%)$ were White, $1,402(1.1 \%)$ were other race and 2,009 $(1.6 \%)$ were missing this information. Melanoma is known to be a disease that predominantly presents in white people. The cohorts of other races were too small for this study so they were all merged into 'other' races. Most patients were insured, 56,247 (44.5\%) had private insurance and 65,588 $(51.9 \%)$ had government insurance. Only 2,408 (1.9\%) had no insurance, while 2,245 (1.8\%) were missing this information. Table I outlines patient demographics and facility type characteristics by receipt of excisional versus other biopsy types. Statistically significant differences were found on all variables on the chi-square test.

As seen in Table II, the results of our multivariate analysis demonstrated that demographic characteristics affected whether patients underwent excisional biopsy or not. Being of Hispanic origin $(\mathrm{OR}=0.63, \mathrm{CI}=0.55-0.71, p<0.01)$, nonwhite $(\mathrm{OR}=0.66, \mathrm{CI}=0.58-0.76, p<0.01)$ or older than 80 years $(\mathrm{OR}=0.77, \mathrm{CI}=0.72-0.81, p<0.01)$ was found to reduce the likelihood of undergoing excisional biopsy when compared to non-Hispanic, White or patients under 80 years of age. Other characteristics, such as female gender $(\mathrm{OR}=1.02, \mathrm{CI}=0.99-1.1, p<0.01)$ or income $<\$ 63,000$ $(\mathrm{OR}=1.03, \mathrm{CI}=0.99-1.074, p<0.01)$ showed no statistically significant effect. Demographic characteristics that increased the likelihood of undergoing excisional biopsy included residing in a rural $(\mathrm{OR}=1.12, \mathrm{CI}=1.07-1.17, p<0.01)$ or urban area $(\mathrm{OR}=1.16, \mathrm{CI}=1.04-1.30, \quad p<0.01)$ when compared to a metropolitan area.

Facility type was also identified as a factor that influenced undergoing excisional biopsy (Table II). Multivariate analysis revealed that patients who received care under Comprehensive Community Cancer Programs ( $\mathrm{OR}=0.33$, $\mathrm{CI}=0.31-0.36, p<0.01)$, Community Cancer Programs $(\mathrm{OR}=0.52, \mathrm{CI}=0.50-0.54, p<0.01)$ or Integrated Network Cancer Programs $(\mathrm{OR}=0.58, \mathrm{CI}=0.55-0.61, p<0.01)$ had reduced odds of undergoing excisional biopsy when compared to Academic/Research Cancer Programs. Facility locations were also associated with statistically significant differences in biopsy type. Using the New England area as reference, we found that patients had higher odds of undergoing excisional biopsy in Middle Atlantic ( $\mathrm{OR}=1.12$,
$\mathrm{CI}=1.05-1.19, p<0.01)$, East North Central $(\mathrm{OR}=1.35$, $\mathrm{CI}=1.27-1.45, p<0.01)$, West North Central (OR=2.40, $\mathrm{CI}=2.22-2.60, p<0.01)$, Mountain $(\mathrm{OR}=1.17, \mathrm{CI}=1.081-1.273$, $p<0.01)$ and Pacific $(\mathrm{OR}=3.53, \mathrm{CI}=3.29-3.79, p<0.01)$ areas.

\section{Discussion}

Melanoma incidence has been rising for over a decade, making prompt diagnosis and treatment crucial for reducing the mortality of this disease $(2,8)$. Excisional biopsy is the standard of care for patients with lesions suspicious for melanoma. However, aesthetics might be a significant concern for patients when it comes to the type of biopsy performed. The risk of having a scar or a significant skin defect that might require flap repair is always a possibility with larger biopsies such as excisional biopsy.

Before the year 2000, literature studies reported that partial biopsies that transected the lesion reduced overall survival $(9,10)$, however, this has not been proven for melanoma (10). Mills and colleagues published a study in 2013 that reported no difference in tumor recurrence or disease-specific survival with biopsy type other than excisional utilizing univariate analysis. The report concluded that shave and punch biopsies, when used appropriately, "should not be discouraged for the diagnosis of melanoma" (11). However, there is also older evidence that states that superficial shave should not be used for pigmented lesions, especially if melanoma is a possible diagnosis $(12,13)$. A more recent study failed to concur with such findings (14) and supported Mills et al. instead. Prospective randomized trials should be performed to solve the dilemma of whether biopsies other than excisional are associated with worse outcomes for patients.

Our study showed that minorities, vulnerable populations such as those over 80 years old, and patients that receive care and non-academic/research institutions have lower odds of undergoing excisional biopsy. Our results are in congruence with several studies (15-17) that have reported disparities in healthcare that commonly affect minorities, patients living in dispersed rural areas or with lower incomes, lower education, or who receive care at nonacademic community hospitals. Schrijvers and colleagues reported better survival outcomes for lung, colorectal, breast, prostate, and uterine cancer in patients that resided in more affluent areas when compared to those in more impoverished socioeconomic areas (15). Similarly, in a 2004 meta-analysis, Subramanian and colleagues observed poverty to be a factor for poor overall health and premature mortality from diseases that are considered curable (16), while in 2006, Cormier and colleagues noted low income as a risk factor for poorer outcomes in cancer (17). Comparing our results to these articles shows that disparities are not limited to melanoma and that they occur frequently in other types of cancer. 
Table I. Patient characteristics according to biopsy type.

\begin{tabular}{|c|c|c|c|c|}
\hline \multirow[b]{2}{*}{ Characteristic } & \multirow[b]{2}{*}{ Subgroup } & \multicolumn{2}{|c|}{ Biopsy type, N (\%) } & \multirow[b]{2}{*}{$p$-Value } \\
\hline & & Excisional & Other & \\
\hline \multirow[t]{3}{*}{ Origin } & Non-Hispanic & $37,016(98)$ & $81,133(99)$ & $<0.01$ \\
\hline & Hispanic & $709(2)$ & $983(1)$ & \\
\hline & Total $(119,841)$ & $37,725(100)$ & $82,116(100)$ & \\
\hline \multirow[t]{4}{*}{ Insurance status } & Private & $18,837(48)$ & $46,751(55)$ & $<0.01$ \\
\hline & None & $1,149(3)$ & $1259(1)$ & \\
\hline & Government & $19,452(49)$ & $36,795(43)$ & \\
\hline & Total $(124,243)$ & $39,438(100)$ & $84,805(100)$ & \\
\hline \multirow[t]{4}{*}{ Population density } & Metropolitan & $32,094(82)$ & $69,772(84)$ & $<0.01$ \\
\hline & Rural & $6,190(16)$ & $11,788(14)$ & \\
\hline & Urban & $698(2)$ & $1,410(2)$ & \\
\hline & Total $(121,952)$ & $38,982(100)$ & $82,970(100)$ & \\
\hline \multirow[t]{5}{*}{ Distance from facility } & $1-200$ miles & $39,350(98)$ & $83,774(98)$ & $<0.01$ \\
\hline & 201-500 miles & $387(1)$ & $1,027(1)$ & \\
\hline & $501-1,000$ miles & $181(0)$ & $337(0)$ & \\
\hline & $>1,000$ miles & $149(0)$ & $404(1)$ & \\
\hline & Total $(125,609)$ & $40,067(100)$ & $85542(100)$ & \\
\hline \multirow[t]{3}{*}{ Race } & White & $39,143(99)$ & $83,934(99)$ & $<0.01$ \\
\hline & Other & $600(1)$ & $802(1)$ & \\
\hline & Total $(124,479)$ & $39,743(100)$ & $84,736(100)$ & \\
\hline \multirow[t]{5}{*}{ Age group } & $<40$ Years & $3,826(9)$ & $8,716(10)$ & $<0.01$ \\
\hline & 40-60 Years & $12,595(31)$ & $28,888(34)$ & \\
\hline & 61-80 Years & $17,696(44)$ & $38,491(45)$ & \\
\hline & $>80$ Years & $6,371(16)$ & $9,905(12)$ & \\
\hline & Total $(126,488)$ & $40,488(100)$ & $86,000(100)$ & \\
\hline \multirow[t]{10}{*}{ Facility location } & New England & $2,687(7)$ & $4,843(6)$ & $<0.01$ \\
\hline & Middle Atlantic & $6,487(18)$ & $12,552(16)$ & \\
\hline & South Atlantic & $9,667(26)$ & $12,127(16)$ & \\
\hline & East North Central & $5,668(15)$ & $11,637(15)$ & \\
\hline & East South Central & 1909 (5) & $2,140(3)$ & \\
\hline & West North Central & $2,523(7)$ & $9,490(12)$ & \\
\hline & West South Central & $1,847(5)$ & $2,164(3)$ & \\
\hline & Mountain & $2,207(6)$ & $4,263(6)$ & \\
\hline & Pacific & $3,667(10)$ & $18,068(23)$ & \\
\hline & Total $(113,946)$ & 36,662 & 77,284 & \\
\hline \multirow[t]{5}{*}{ Facility type } & Academic/research & $15,285(42)$ & $43,463(56)$ & $<0.01$ \\
\hline & Comprehensive Community & $3,486(10)$ & $3,101(4)$ & \\
\hline & Community & 14,309 (39) & $25,969(34)$ & \\
\hline & Integrated Network & $3,582(10)$ & $4,751(6)$ & \\
\hline & Total $(113,946)$ & 36,662 & 77,284 & \\
\hline \multirow[t]{3}{*}{ Gender } & Male & $23,367(58)$ & $48,686(57)$ & $<0.01$ \\
\hline & Female & $17,121(42)$ & $37,314(43)$ & \\
\hline & Total $(126,488)$ & 40,488 & 86,000 & \\
\hline \multirow[t]{3}{*}{ Average income } & $\geq \$ 63,000$ & $15,150(38)$ & $38,612(45)$ & $<0.01$ \\
\hline & $<\$ 63,000$ & $24,921(62)$ & $46,888(55)$ & \\
\hline & Total $(125,571)$ & 40,071 & 85,500 & \\
\hline \multirow[t]{5}{*}{ Education* } & $<7 \%$ & $12,499(31)$ & $33,958(40)$ & $<0.01$ \\
\hline & $7-12.9 \%$ & $14,454(36)$ & $30,147(35)$ & \\
\hline & $13-20.9 \%$ & $9,117(23)$ & $15,342(18)$ & \\
\hline & $>21 \%$ & $4,027(10)$ & $6,088(7)$ & \\
\hline & Total $(125,632)$ & 40,097 & 85,535 & \\
\hline
\end{tabular}

Community: Community Cancer Program. *Percentage with high-school diploma. 
Table II. Odds ratio of undergoing excisional biopsy of melanoma.

\begin{tabular}{|c|c|c|}
\hline Characteristic & OR $(95 \% \mathrm{CI})$ & $p$-Value \\
\hline \multicolumn{3}{|l|}{ Origin } \\
\hline Non-Hispanic & 1 & \\
\hline Hispanic & $0.627(0.553-0.711)$ & $<0.01$ \\
\hline \multicolumn{3}{|l|}{ Insurance status } \\
\hline Private & 1 & \\
\hline None & $0.529(0.475-0.588)$ & $<0.01$ \\
\hline Government & $0.923(0.888-0.960)$ & $<0.01$ \\
\hline \multicolumn{3}{|l|}{ Population density } \\
\hline Metropolitan & 1 & \\
\hline Rural & $1.121(1.072-1.171)$ & $<0.01$ \\
\hline Urban & $1.163(1.04-1.302)$ & $<0.01$ \\
\hline \multicolumn{3}{|l|}{ Distance from facility } \\
\hline 1-200 miles & 1 & \\
\hline 201-500 miles & $0.853(0.735-0.990)$ & 0.036 \\
\hline $501-1,000$ miles & $0.667(0.532-0.837)$ & $<0.01$ \\
\hline$>1,000$ miles & $1.077(0.854-1.359)$ & 0.529 \\
\hline \multicolumn{3}{|l|}{ Race } \\
\hline White & 1 & \\
\hline Other & $0.662(0.575-0.761)$ & $<0.01$ \\
\hline \multicolumn{3}{|l|}{ Age group } \\
\hline 40-60 Years & 1 & \\
\hline 61-80 Years & $1.012(0.972-1.053)$ & 0.574 \\
\hline$>80$ Years & $0.765(0.724-0.808)$ & $<0.01$ \\
\hline \multicolumn{3}{|l|}{ Facility location } \\
\hline New England & 1 & \\
\hline Middle Atlantic & $1.118(1.046-1.194)$ & $<0.01$ \\
\hline South Atlantic & $0.778(0.729-0.831)$ & $<0.01$ \\
\hline East North Central & $1.358(1.268-1.453)$ & $<0.01$ \\
\hline East South Central & $0.917(0.836-1.006)$ & 0.068 \\
\hline West North Central & $2.403(2.224-2.596)$ & $<0.01$ \\
\hline West South Central & $1.013(0.922-1.113)$ & 0.783 \\
\hline Mountain & $1.173(1.081-1.273)$ & $<0.01$ \\
\hline Pacific & $3.534(3.291-3.794)$ & $<0.01$ \\
\hline \multicolumn{3}{|l|}{ Facility type } \\
\hline Academic/Research & 1 & \\
\hline Comprehensive Community & $0.333(0.313-0.355)$ & $<0.01$ \\
\hline Community & $0.517(0.500-0.535)$ & $<0.01$ \\
\hline Integrated Network & $0.579(0.548-0.612)$ & $<0.01$ \\
\hline \multicolumn{3}{|l|}{ Gender } \\
\hline Male & 1 & \\
\hline Female & $1.019(0.988-1.050)$ & 0.233 \\
\hline \multicolumn{3}{|l|}{ Income } \\
\hline$\geq \$ 63,000$ & 1 & \\
\hline$<\$ 63,000$ & $1.033(0.994-1.074)$ & 0.101 \\
\hline \multicolumn{3}{|l|}{ Education* } \\
\hline \multicolumn{3}{|l|}{$<7 \%$} \\
\hline $7-12.9 \%$ & $0.841(0.808-0.875)$ & $<0.01$ \\
\hline $13-20.9 \%$ & $0.764(0.727-0.803)$ & $<0.01$ \\
\hline$>21 \%$ & $0.721(0.676-0.769)$ & $<0.01$ \\
\hline
\end{tabular}

CI: Confidence interval; OR: odds ratio; Community: Community Cancer Program. *Percentage with high-school diploma.

Unfortunately, as in most fields of medicine, disparities affecting patients with lower income and lower education, minorities, and those without insurance have been reported in melanoma treatment and outcomes (2-4). Our study showed that these disparities are also present in regard to the type of biopsy that patients undergo. For example, when adjusted for confounders, Hispanic origin, government insurance or no insurance, non-White race and living in a zip code with a higher percentage of people without a high school diploma reduces the likelihood of an excisional biopsy.

Our study is not without limitations. The NCDB is a database that records approximately $70 \%$ of patients newly diagnosed with cancer in the US, but its fidelity is subject to every institution's compliance with accurately reporting all generated information. Furthermore, the NCDB has only one section for reporting the procedure performed on each patient. As a result, most patients did not have biopsy procedures reported, causing us to exclude a large number of patients from our study. Moreover, melanoma is a disease that affects primarily White people, making the cohort of other races substantially smaller. Another limitation of our study is that patients reported with excisional biopsy may have undergone a different type of biopsy initially followed by excisional biopsy based on the initial biopsy report.

This is, to our knowledge, the first study that evaluated disparities in the type of biopsy that patients with melanoma undergo. From the results, we learned that efforts need to be made to increase compliance with guidelines and further studies are needed to identify causality of disparities in the initial approach to melanoma.

\section{Conflicts of Interest}

All Authors report no conflicts of interest in regard to this study.

\section{Authors' Contributions}

All Authors contributed to the study design, commented on previous versions of the article, read and approved the final article. Material preparation, data collection and analysis were performed by DJR, ACS and AJF. The first draft of the article was written by DJR and MTH.

\section{Acknowledgements}

This study was supported in part by the Mayo Clinic Robert D. and Patricia E. Kern Center for the Science of Health Care Delivery and Center for Individualized Medicine.

\section{References}

1 Lorimer PD, Benham EC, Walsh K, Han Y, Forster MR, Sarantou T, White RL Jr. and Hill JS: Reporting of mitotic rate in cutaneous melanoma: A study using the National Cancer Data Base. J Surg Oncol 115(3): 281-286, 2017. PMID: 28335082. DOI: $10.1002 /$ jso. 24503

2 Sitenga JL, Aird G, Ahmed A, Walters R and Silberstein PT: Socioeconomic status and survival for patients with melanoma in the United States: An NCDB analysis. Int J Dermatol 57(10): 1149-1156, 2018. PMID: 29736922. DOI: 10.1111/ijd.14026 
3 Dawes SM, Tsai S, Gittleman H, Barnholtz-Sloan JS and Bordeaux JS: Racial disparities in melanoma survival. J Am Acad Dermatol 75(5): 983-991, 2016. PMID: 27476974. DOI: 10.1016/j.jaad.2016.06.006

4 Forsea AM, Del Marmol V, Stratigos A and Geller AC: Melanoma prognosis in Europe: Far from equal. Br J Dermatol 171(1): 179182, 2014. PMID: 24588115. DOI: 10.1111/bjd.12923

5 Coit DG, Andtbacka R, Anker CJ, Bichakjian CK, Carson WE, 3rd, Daud A, Dimaio D, Fleming MD, Guild V, Halpern AC, Hodi FS Jr., Kelley MC, Khushalani NI, Kudchadkar RR, Lange JR, Lind A, Martini MC, Olszanski AJ, Pruitt SK, Ross MI, Swetter SM, Tanabe KK, Thompson JA, Trisal V, Urist MM, McMillian N, Ho $\mathrm{M}$ and National Comprehensive Cancer Network: Melanoma, version 2.2013: Featured updates to the NCCN guidelines. J Natl Compr Canc Netw 11(4): 395-407, 2013. PMID: 23584343.

6 Bichakjian CK, Halpern AC, Johnson TM, Foote Hood A, Grichnik JM, Swetter SM, Tsao H, Barbosa VH, Chuang TY, Duvic M, Ho VC, Sober AJ, Beutner KR, Bhushan R, Smith Begolka W and American Academy of D: Guidelines of care for the management of primary cutaneous melanoma. American Academy of Dermatology. J Am Acad Dermatol 65(5): 10321047, 2011. PMID: 21868127. DOI: 10.1016/j.jaad.2011.04.031

7 Bilimoria KY, Stewart AK, Winchester DP and Ko CY: The National Cancer Data Base: A powerful initiative to improve cancer care in the United States. Ann Surg Oncol 15(3): 683690, 2008. PMID: 18183467. DOI: 10.1245/s10434-007-9747-3

8 Sisti A, Tassinari J, Milonia L, Grimaldi L and Nisi G: Limberg flap for surgical treatment of melanoma. Plast Reconstr Surg 138(3): 565e-566e, 2016. PMID: 27152594. DOI: 10.1097/ prs.0000000000002458

9 Rampen FH and van der Esch EP: Biopsy and survival of malignant melanoma. J Am Acad Dermatol 12(2 Pt 1): 385-388, 1985. PMID: 3973139. DOI: 10.1016/s0190-9622(85)80081-5
10 Austin JR, Byers RM, Brown WD and Wolf P: Influence of biopsy on the prognosis of cutaneous melanoma of the head and neck. Head Neck 18(2): 107-117, 1996. PMID: 8647675. DOI: 10.1002/(SICI)1097-0347(199603/04)1 8:2<107::AIDHED1>3.0.CO;2-5

11 Mills JK, White I, Diggs B, Fortino J and Vetto JT: Effect of biopsy type on outcomes in the treatment of primary cutaneous melanoma. Am J Surg 205(5): 585-590; discussion 590, 2013. PMID: 23592167. DOI: 10.1016/j.amjsurg.2013.01.023

12 Pinkus H: Skin biopsy: A field of interaction between clinician and pathologist. Cutis 20(5): 609-614, 1977. PMID: 923285.

13 Arca MJ, Biermann JS, Johnson TM and Chang AE: Biopsy techniques for skin, soft-tissue, and bone neoplasms. Surg Oncol Clin N Am 4(1): 157-174, 1995. PMID: 7697456.

14 Pflugfelder A, Weide B, Eigentler TK, Forschner A, Leiter U, Held L, Meier F and Garbe C: Incisional biopsy and melanoma prognosis: Facts and controversies. Clin Dermatol 28(3): 316-318, 2010. PMID: 20541685. DOI: 10.1016/j.clindermatol.2009.06.013

15 Schrijvers CT, Mackenbach JP, Lutz JM, Quinn MJ and Coleman MP: Deprivation, stage at diagnosis and cancer survival. Int J Cancer 63(3): 324-329, 1995. PMID: 7591225.

16 Subramanian SV and Kawachi I: Income inequality and health: What have we learned so far? Epidemiol Rev 26: 78-91, 2004. PMID: 15234949. DOI: 10.1093/epirev/mxh003

17 Cormier JN, Xing Y, Ding M, Lee JE, Mansfield PF, Gershenwald JE, Ross MI and Du XL: Ethnic differences among patients with cutaneous melanoma. Arch Intern Med 166(17): 1907-1914, 2006. PMID: 17000949. DOI: 10.1001/archinte.166.17.1907

Received September 2, 2019

Revised September 18, 2019 Accepted September 19, 2019 